\title{
Playing by the Rules
}

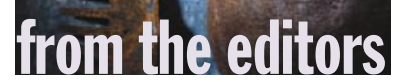

\author{
Charlene O'Hanlon, ACM Queue
}

$S$ ome of my favorite childhood memories are of playing games with my sister-both structured games such as Monopoly or hopscotch and imaginationfueled games such as cops and robbers or roller derby girls (don't ask). Regardless of whether the game had established regulations, often our play would devolve into what I call Calvinball, a term coined in the comic strip Calvin and Hobbes referring to the act of making up the rules as you go along.

Our Calvinball play had some distinct advantages: It was a lot more fun to change the rules in the middle of the game. No one ever got bored. It allowed us to stretch our minds beyond the parameters of regular play. And-quite possibly the best advantage—everybody won in Calvinball. Of course, there was the occasional cry of, "Hey, that's not fair!" but that person was quickly outnumbered if there were more than two players.

Unfortunately (at least for me), life doesn't work that way. Calvinball would never fly in the corporate environment. Results are based on expectations, and expectations are based on rules. Things can get messy if that path is not followed. Rules and regulations bring a sense of order, and order has more of a place in the corporate world than in childhood games.

Compliance is one very large way of imposing order and ensuring everyone plays by the same rules. Corporate financial shenanigans, most notably the Enron debacle a few years back, have brought on a plethora of new compliance regulations including the Sarbanes-Oxley Act of 2002 (more commonly known as SOX) and Basel II (aka The New Accord, or its given name of the International Convergence of Capital Measurement and Capital Standards-A Revised Framework). HIPAA (the Health Insurance Portability and Accountability Act of 1996), which was originally designed to protect employees from losing their health insurance coverage should they leave their jobs for any reason, has spawned a reformation of the health-care industry as it relates to privacy and protection of a patient's personal information. The HL7 (Health Level 7) standard developed by the organization of the same name is now the de facto standard for interfacing disparate health-related software systems.

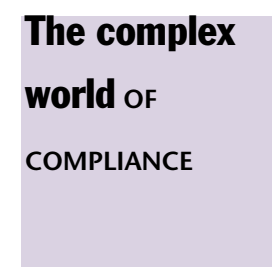

The impact of these compliance regulations and resulting standards has had a ripple effect throughout the entire corporate

spectrum, from Fortune 500 companies to mom-and-pop shops. Developers and IT departments now must scrutinize every application, purchase, and implementation with an eye toward compliance. IT budgets have been stretched to deal with myriad issues associated with becoming compliant.

It's not an easy task, but savvy IT managers can keep their organizations compliant while staying within the parameters of their budgets. The best developers can help make that seemingly impossible dream a reality. CIOs, on the other hand, are tasked with helping ensure success by providing both a workable budget and smart, dedicated people-a delicate balance at best.

This issue of $A C M$ Queue attempts to deal with compliance head-on, but admittedly only scratches the surface. Compliance generates subtopics like a rabbit generates bunnies, so if there is a compliance-related topic we haven't covered that you would like to read about, please let us know.

On a totally unrelated note, this month's issue also features the debut of a new monthly column devoted to technology outside the workplace. Geek@home explores how technologists can-and do-use their wares to improve their lives and the lives of those around them. Contributor Mache Creeger kicks things off with his internal argument over installing a terabyte server in his home. The column promises to be an interesting and mostly lighthearted read, and might even offer a few takeaways to spur you into action. Again, let us know what you think, and what you would like to read about.

Keeping up with compliance is a difficult and consuming task. In this instance, however, I'd rather have real rules than Calvinball. $\mathrm{Q}$

CHARLENE O'HANLON, editor of ACM Queue, believes everyone could benefit from a good game of Calvinball. You can reach her via e-mail at cohanlon@acmqueue.com. 